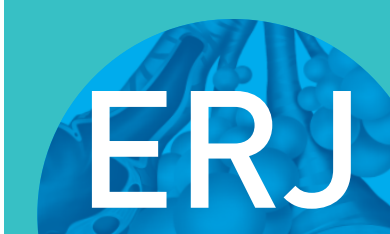

open research

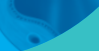

\title{
Volatile organic compound profiles in outlet air from extracorporeal life- support devices differ from breath profiles in critically ill patients
}

\author{
Jan Hendrik Leopold', Alois Philipp², Thomas Bein², Andreas Redel², \\ Michael Gruber², Marcus J. Schultz ${ }^{1,3}$, Ameen Abu-Hanna1, Paul Brinkman, \\ Hans-Gerd Janssen ${ }^{4}$ and Lieuwe D.J. Bos (1) ${ }^{1}$
}

\section{ABSTRACT}

Introduction: It is highly uncertain whether volatile organic compounds (VOCs) in exhaled breath of critically ill intensive care unit patients are formed in the lung locally, in the air compartment or lung tissue, or elsewhere in the body and transported to the lung via the bloodstream. We compared VOC mixtures in exhaled breath and in air coming from extracorporeal support devices in critically ill patients to address this issue.

Methods: First, we investigated whether it was safe to connect an electronic nose (eNose) or a gas sampling pump to extracorporeal support membranes. Then, breath and air from extracorporeal support devices were collected simultaneously for continuous monitoring of VOC mixtures using an eNose. In addition, samples for gas chromatography/mass spectrometry (GC-MS) analysis were taken daily at the two measurement sites.

Results: 10 critically ill patients were monitored for a median (interquartile range) duration of 73 (72-113) h; in total, we had $887 \mathrm{~h}$ of air sampling. The eNose signals of breath correlated moderately with signals of air from the extracorporeal support devices $\left(\mathrm{R}^{2}=0.25-0.44\right)$. After GC-MS analysis, 96 VOCs were found both in breath and air from the extracorporeal support devices; of these, 29 (30\%) showed a significant correlation $(\mathrm{p}<0.05)$ between the two measurement sites, of which 17 were identified. VOCs that did not correlate were found in a higher concentration in breath than in air from the extracorporeal support devices.

Conclusion: This study suggests VOC analysis in the extracorporeal circulation is safe, and that VOCs of nonpulmonary origin can be measured in the breath and in the extracorporeal circulation of critically ill patients. For VOCs that did not correlate between the two measurement sites, the breath concentration was higher, suggesting pulmonary production of these molecules in a highly selected population of patients that received extracorporeal support.

@ERSpublications

Systemically produced VOCs in exhaled breath and extracorporeal circulation correlate well. About one in three VOCs do not correlate and are found in higher concentrations in breath, suggesting pulmonary production of these VOCs. http://ow.ly/cbjt30nMXY5

Cite this article as: Leopold JH, Philipp A, Bein T, et al. Volatile organic compound profiles in outlet air from extracorporeal life-support devices differ from breath profiles in critically ill patients. ERJ Open Res 2019; 5: 00134-2018 [https://doi.org/10.1183/23120541.00134-2018].

This article has supplementary material available from openres.ersjournals.com

Received: Aug 112018 | Accepted after revision: Dec 152018

Copyright $\odot E R S$ 2019. This article is open access and distributed under the terms of the Creative Commons Attribution Non-Commercial Licence 4.0. 


\section{Introduction}

Intensive care medicine requires intensive monitoring of numerous biological markers indicative for organ function, infection status or metabolic needs. Often, these markers are blood based and can only be analysed intermittently. Preferably, biological data are monitored continuously and as noninvasively as possible in critically ill patients [1].

Exhaled breath contains hundreds of volatile organic compounds (VOCs) [2]. Analysis of VOCs has been suggested to provide information about numerous pathophysiological processes, and might improve the diagnosis and monitoring of several diseases [3-6]. VOCs can be separated, quantified and identified by gas chromatography/mass spectrometry (GC-MS). Alternatively, patterns of VOCs can be analysed by sensor arrays called electronic noses (eNoses). VOCs result from oxidative stress [3], inflammation [7] or come from bacterial metabolism [7-9] and can be of systemic origin or can be produced in the lung itself. Studies in healthy volunteers have established that certain VOCs, such as acetone, are transported to the lung via the bloodstream [6]. Others, such as propofol, are infused by the physician and we therefore know the biological origin of propofol in exhaled breath [10]. However, the origin of many VOCs that are encountered in severe illness is still unknown.

Patients with severe respiratory or circulatory problems who are admitted to the intensive care unit (ICU) may receive extracorporeal life support to assist with oxygenation (extracorporeal membrane oxygenation) or for carbon dioxide $\left(\mathrm{CO}_{2}\right)$ removal (extracorporeal $\mathrm{CO}_{2}$ removal). The application of these extracorporeal support devices allows for the comparison of (profiles of) VOCs coming from the external air outlet of the membrane with those in exhaled air.

We hypothesise that there is a correlation between VOCs in exhaled breath and VOCs coming from the membrane of an extracorporeal support device for VOCs that are known to be of systemic origin in critically ill patients requiring extracorporeal support. If so, we will use this technique to identify those compounds that are likely to have a nonpulmonary origin in critical illness. The aims of this study are: 1) to assess the feasibility and safety of connecting an eNose to an extracorporeal circulation device, and 2) to evaluate the correlation between VOCs in exhaled breath and VOCs coming from the membrane of an extracorporeal support device.

\section{Methods}

Design

Feasibility, safety and clinical measurements were all assessed at the University Hospital Regensburg (Regensburg, Germany). The Institutional Review Board of the University Hospital Regensburg waived the need for informed consent due to the noninvasive nature of the study and the established safety of breath analysis in mechanically ventilated patients [1].

\section{VOC analysis}

VOCs were measured in exhaled breath and in the extracorporeal circulation using two different techniques. First, air was monitored continuously using an eNose adapted for clinical use (Comon Invent, Delft, The Netherlands). This device is composed of a sensor array with four metal oxide sensors (Figaro, Osaka, Japan) and has been described in a previous study [11]. The eNose was connected to the membrane of the extracorporeal support device via an intermediate piece of tubing to the external outlet of the membrane. Samples for GC-MS were gathered with a gas sampling pump (ActiVOC; Markes, Llantrisant, UK) from the same disposable side-stream connection at $200 \mathrm{~mL} \cdot \mathrm{min}^{-1}$ for $10 \mathrm{~min}$ and trapped on a sorbent tube (TD100; Markes) $[12,13]$. These tubes were analysed by means of GC-MS as described previously [14]. In short, sorbent tubes were heated to $280^{\circ} \mathrm{C}$ for $15 \mathrm{~min}$ with a flow rate of $30 \mathrm{~mL} \cdot \mathrm{min}^{-1}$. VOCs were captured on a cold trap at $10^{\circ} \mathrm{C}$ and then reinjected by rapidly heating the trap to $300^{\circ} \mathrm{C}$ for $1 \mathrm{~min}$. Subsequently the molecules were splitless injected through a transfer line at $180^{\circ} \mathrm{C}$ onto an Inertcap 5MS/Sil GC column $(30 \mathrm{~m}$, internal diameter $0.25 \mathrm{~mm}$, film thickness $1 \mu \mathrm{m}$, 1,4-bis(dimethylsiloxy)phenylene dimethyl polysiloxane; Restek, Breda, The Netherlands) with a flow rate of $1.2 \mathrm{~mL} \cdot \mathrm{min}^{-1}$. Oven temperature was isothermal at $40^{\circ} \mathrm{C}$ for $5 \mathrm{~min}$, increased to $280^{\circ} \mathrm{C}$ at $10^{\circ} \mathrm{C} \cdot \mathrm{min}^{-1}$ and kept isothermal at $280^{\circ} \mathrm{C}$ for $5 \mathrm{~min}$. Molecules were ionised using electron ionisation $(70 \mathrm{eV})$ and the fragment ions were detected using a quadrupole mass spectrometer (GCMS-GP2010; Shimadzu, Den

Affiliations: ${ }^{1}$ Dept of Intensive Care Medicine, Amsterdam UMC, University of Amsterdam, Amsterdam, The Netherlands. ${ }^{2}$ Dept of Intensive Care, University Hospital Regensburg, Regensburg, Germany. ${ }^{3}$ Dept of Intensive Care, Mahidol Oxford Tropical Medicine Research Unit, Bangkok, Thailand. "Faculty of Science, University of Amsterdam, Amsterdam, The Netherlands.

Correspondence: Lieuwe D.J. Bos, Dept of Intensive Care Medicine, M0-127, Academic Medical Center, Meibergdreef 9, 1105 AZ Amsterdam, The Netherlands. E-mail: I.d.bosdamc.uva.nl 
Bosch, The Netherlands) with a scan range of 37-300 Da. GC-MS analysis, de-noising, peak detection and alignment were performed using the $\mathrm{R}$ package Xcms (Scripps Center for Metabolomics, La Jolla, CA, USA) and resulted in an ion fragment peak table as input for statistical analysis. Collinearity of ion fragment peaks was checked for every detected peak in the total ion chromatogram to exclude co-elution that would significantly increase the measured VOC concentration. The predictive VOCs were manually checked in the raw chromatograms and the corresponding metabolites were tentatively identified based on National Institute of Standards and Technology (Gaithersburg, MD, USA) library matching. Metabolites were considered as identified if the first five hits in the library were the same compound and all matching factors were $90 \%$. In the case of multiple likely library hits, a chemical standard (Sigma-Aldrich, Zwijndrecht, The Netherlands) was injected for identification. When these two procedures did not result in identification, the compound was deemed unidentified.

\section{Extracorporeal circulation}

Feasibility and safety

Since the operation of extracorporeal support devices should in no way be disturbed, it had to be investigated whether it was safe to connect an eNose or a gas sampling pump to the device. Therefore, it was tested if the connector, a T-piece with the same diameter as the gas outlet, added airflow resistance that could possibly disturb the extracorporeal support device. Additionally, the connection had to be tested to make sure that no condensed water droplets entered into the eNose together with the airflow. The gas inlet of the membrane was connected to the hospital oxygen supply. A cuff blood pressure meter was placed in front of the inlet port with a three-way valve. The adapter to which the eNose or gas sampling pump could be connected was placed on the gas outlet of the membrane. An eNose or gas sampling pump was connected to this adapter. Pre-oxygenator pressure data were recorded with and without the connector in triplicate at three different in-membrane pressures $(60,120$ and $150 \mathrm{mmHg})$ using 15 different levels of sweep gas flow $\left(1-15 \mathrm{~L} \cdot \mathrm{min}^{-1}\right)$. These measurements were performed using the different membranes used in the University Hospital Regensburg: Maquet Quadrox-iR and HLS Advanced 7.0 (Maquet, Rastatt, Germany), Novalung iLA Activve (Inspiration Healthcare, Earl Shilton, UK), Sorin ECC.O 5 (Sorin, Munich, Germany) and Medos HILITE AF7000 (Medos, Stolberg, Germany). Mean difference in in-membrane pressure and the range of differences was calculated afterwards.

\section{Measurements in patients}

After safety was guaranteed, measurements in patients were started. Inclusion criteria for patients were: 1) admitted to an ICU of the University Hospital Regensburg, 2) received extracorporeal support and 3) were expected to receive extracorporeal support for at least $72 \mathrm{~h}$. There were no exclusion criteria. Due to the exploratory nature of the study, every available patient between September and December 2015 was included and no power calculation was made. eNose measurements were taken during the entire duration of extracorporeal support. Every $24 \mathrm{~h}$ an air sample was taken for GC-MS analysis. When a patient was monitored for 7 days and another eligible patient was available, the eNose was transferred to the new patient. Patient characteristics and oxygenator variables were collected.

\section{Breath measurements}

Breath was monitored through a side-stream connector placed distal to the heat and moisture exchanger, as described previously $[12,15]$. The eNose was connected to the side-stream connector with Teflon tubing. As with the extracorporeal circulation measurements, eNose measurements were taken during the entire duration of extracorporeal support. Breath samples for GM-MS analyses were taken simultaneously with those taken from the extracorporeal circulation.

\section{Pre-processing of the eNose signal}

Using available ventilator and oxygenator variables, eNose data were pre-processed to diminish the effect of changes in humidity in exhaled breath and air coming from the membrane. This approach has been discussed in detail previously [15]. In short, the pre-processing included normalisation for changes in humidity and smoothing of the signal.

\section{Data analysis}

After eNose data were pre-processed, each sensor was correlated to the corresponding sensor at both measurement sites for each patient using the $\operatorname{lm}()$ method in $\mathrm{R}$ version 3.3.1 for linear regression modelling [16]. VOCs, measured by GC-MS, were correlated between the two measurement sites in a similar fashion. The abundance of the VOCs was also compared between the breath and the extracorporeal circulation, and a ratio was calculated. The association between the correlation coefficient and the breath/extracorporeal circulation ratio was visualised and was analysed by linear regression. 


\section{Results}

Between September and December 2015, 10 patients were included in the study. Median (interquartile range (IQR)) patient age was 56 (51-65) years and all patients were critically ill. Six out of 10 patients were diagnosed with acute respiratory distress syndrome. Patients were admitted at the ICU for a median (IQR) duration of 36 (35-57) days and monitored by the eNose for a median (IQR) duration of 73 (72-113) h. A total of $887 \mathrm{~h}$ of eNose data was collected. Patient characteristics are described in table 1.

\section{Feasibility and safety}

The eNose and thermal desorption tube sampling device had no effect on pre-oxygenator pressure in the four different membranes that were tested. Table 2 shows the mean additional pre-oxygenator pressure for the four different membranes at several in-membrane pressures. This indicated that we could safely connect the eNose to the membrane without interfering with extracorporeal life support.

\section{eNose measurements}

eNose signals are based on pattern recognition and do not contain information on quantities of individual VOCs. Therefore, the most important outcome of the present analysis is the correlation between the eNose signals coming from the extracorporeal circulation and breath. A mean $\mathrm{R}^{2}$ of 0.37 (95\% CI 0.15-0.59), 0.44 (95\% CI 0.21-0.67), 0.25 (95\% CI 0.02-0.49) and 0.44 (95\% CI 0.21-0.68) was found for sensors $1-4$, respectively. Correlation plots for the four sensors can be found in figure 1, overlapping all patients with hundreds of repeated measures per patient. Individual plots can be found in the supplementary material.

\section{GC-MS measurements}

At 69 sample instances, a total of 96 different VOCs were found by GC-MS in the breath and in the outlet gas from the extracorporeal circulation. Of these 96 VOCs, 29 (30\%) showed a significant correlation $(p<0.05)$ between the two measurement sites; 17 VOCs that correlated significantly were identified (table 3 and figure 2). These included VOCs from well-described endogenous sources (e.g. 2-methyl-3-hexanone, acetone and ethyl acetate), VOCs from possible exogenous sources (e.g. D-limonene and chlorobenzene) and VOCs due to anaesthetics (propofol and 1,1,1,3,3,3-hexafluoro-2-propanol (metabolite of sevoflurane)). Figure 3 shows the fold change between the exhaled breath concentration and extracorporeal air concentration, and the correlation coefficient between the two measurement sites. A lower correlation between the two measurement sites was associated with a higher concentration of the molecule in breath compared with the extracorporeal air (figure 3).

\section{TABLE 1 Patient characteristics}

\begin{tabular}{|c|c|}
\hline Patients & 10 \\
\hline Age years & $56(51-65)$ \\
\hline Male & $4(40)$ \\
\hline Caucasian & $10(100)$ \\
\hline \multicolumn{2}{|l|}{ Diagnosis } \\
\hline ARDS & $6(60)$ \\
\hline Hypercapnia & $2(20)$ \\
\hline Cardiogenic shock & $1(10)$ \\
\hline Pulmonary embolism & $1(10)$ \\
\hline \multicolumn{2}{|l|}{ Type of extracorporeal circulation } \\
\hline ECMO & $8(80)$ \\
\hline Oxygen flow rate $L \cdot \mathrm{min}^{-1}$ & $62.4 \pm 1.3$ \\
\hline $\mathrm{ECCO}_{2} \mathrm{R}$ & $2(20)$ \\
\hline Oxygen flow rate $L \cdot \mathrm{min}^{-1}$ & $5.2 \pm 1.3$ \\
\hline \multicolumn{2}{|l|}{ Respiratory variables } \\
\hline Minute ventilation $L \cdot \min ^{-1}$ & $8.0 \pm 2.9$ \\
\hline Tidal volume $\mathrm{mL}$ & $412 \pm 158$ \\
\hline PEEP $\mathrm{cmH}_{2} \mathrm{O}$ & $11 \pm 4.5$ \\
\hline ICU LOS days & $36(35-57)$ \\
\hline Duration of eNose monitoring $h$ & $73(72-113)$ \\
\hline
\end{tabular}




\begin{tabular}{|c|c|c|}
\hline Membrane ${ }^{\#}$ & In-membrane pressure $\mathrm{mmHg}$ & Additional pressure $\mathrm{cmH}_{2} \mathrm{O}$ \\
\hline \multirow[t]{3}{*}{ Maquet } & 60 & $-0.56(-2.00-0.33)$ \\
\hline & 120 & $-0.18(-3.00-1.33)$ \\
\hline & 150 & $0.07(-1.33-1.00)$ \\
\hline \multirow[t]{3}{*}{ Medos } & 60 & $-0.04(-0.67-0.33)$ \\
\hline & 120 & $-0.02(-1.00-0.67)$ \\
\hline & 150 & $0.04(-0.33-0.33)$ \\
\hline \multirow[t]{3}{*}{ Novalung } & 60 & $-0.11(-1.33-0.00)$ \\
\hline & 120 & $-0.31(-1.33-0.00)$ \\
\hline & 150 & $-0.04(-0.67-0.33)$ \\
\hline \multirow[t]{3}{*}{ Sorin } & 60 & $-0.04(-0.67-0.00)$ \\
\hline & 120 & $-0.16(-1.00-0.33)$ \\
\hline & 150 & $0.00(0.00-0.00)$ \\
\hline
\end{tabular}

\section{Discussion}

VOC analysis from the gas outlet of the extracorporeal support membrane was considered safe, as it did not increase pre-oxygenator pressure. With eNose measurements, a moderate correlation was found between the two measurement sites, after correction for ventilator settings, suggesting that at least part of the exhaled VOCs are of nonpulmonary origin in critically ill mechanically ventilated ICU patients with severe pulmonary problems. Several VOCs that are known to originate from the circulation (e.g. acetone and propofol) were found to correlate strongly between exhaled breath and the gas outlet of the extracorporeal circulation. However, two-thirds of the VOCs that were found in breath and in the gas
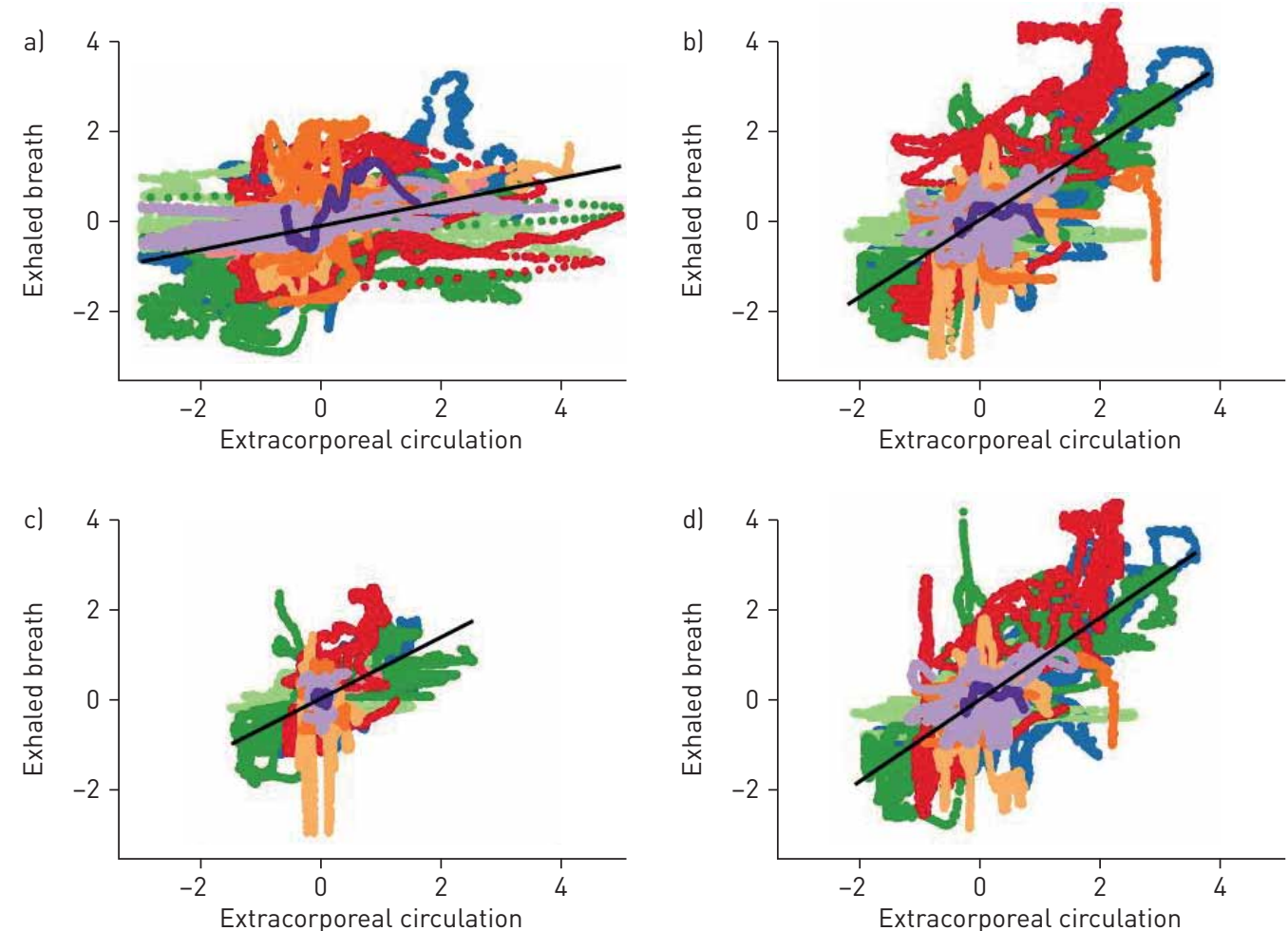

FIGURE 1 Correlation plots for eNose sensor values: breath sensor values plotted against extracorporeal membrane oxygenation sensor values for al sensor 1 , b) sensor $2, c$ ) sensor 3 and d) sensor 4 . Each colour represents a different patient. The black line represents the correlation between the two measurement sites. 
TABLE 3 Volatile organic compounds showing a significant correlation ( $r$ ) between the external outlet of the membrane and the outlet of the tube of the ventilator

\begin{tabular}{|c|c|c|c|c|c|}
\hline $\begin{array}{l}\text { Retention } \\
\text { time min }\end{array}$ & $\mathbf{r}$ & p-value & $\begin{array}{l}\text { Proportion } \\
\text { breath/ECMO }\end{array}$ & Identity & $\begin{array}{l}\text { Presumed } \\
\text { source }\end{array}$ \\
\hline 2.32 & 0.56 & 0.0018 & 0.61 & Acetone & Endogenous \\
\hline 2.47 & 0.37 & 0.0472 & 0.55 & Isoprene & Endogenous \\
\hline 2.78 & 0.84 & 0.0000 & 0.99 & 2-Propanol, 1,1,1,3,3,3-hexafluoro- & Anaesthetic \\
\hline 3.22 & 0.38 & 0.0395 & 1.26 & 1-Propanol & Exogenous \\
\hline 3.50 & 0.45 & 0.0139 & 0.4 & Pentane, 3-methyl- & Endogenous? \\
\hline 3.80 & 0.41 & 0.0255 & 1 & Pentane, 2,4-dimethyl- & Endogenous? \\
\hline 4.20 & 0.48 & 0.0090 & 0.80 & Furan, 2-methyl & Exogenous \\
\hline 4.22 & 0.53 & 0.0029 & 0.54 & Ethyl acetate & Endogenous \\
\hline 5.78 & 0.43 & 0.0197 & 0.99 & 2,4-Hexadiyne & Exogenous \\
\hline 7.33 & 0.89 & 0.0000 & 1 & 1-Pentene, 2,4,4-trimethyl- & Exogenous \\
\hline 8.85 & 0.82 & 0.0000 & 1.18 & Unknown & \\
\hline 9.72 & 0.38 & 0.0431 & 1.27 & Unknown & \\
\hline 9.83 & 0.79 & 0.0000 & 1.19 & Unknown & \\
\hline 11.40 & 0.62 & 0.0004 & 0.89 & Unknown & \\
\hline 11.47 & 0.67 & 0.0001 & 0.83 & Benzene, chloro- & Exogenous \\
\hline 11.95 & 0.68 & 0.0000 & 0.41 & 3-Hexanone, 2-methyl- & Endogenous? \\
\hline 14.47 & 0.56 & 0.0015 & 0.83 & 2-Propanol, 1,1,1-trichloro-2-methyl- & Exogenous \\
\hline 14.47 & 0.70 & 0.0000 & 0.99 & Unknown & \\
\hline 14.88 & 0.41 & 0.0286 & 0.62 & Pentane, 2,2,3-trimethyl- & \\
\hline 15.23 & -0.44 & 0.0161 & 6.35 & Unknown & \\
\hline 15.55 & 0.73 & 0.0000 & 1.22 & D-Limonene & Exogenous \\
\hline 17.07 & 0.60 & 0.0006 & 0.90 & Unknown & \\
\hline 18.55 & 0.67 & 0.0001 & 0.66 & Undecane & Endogenous? \\
\hline 19.03 & 0.62 & 0.0003 & 0.84 & Unknown & \\
\hline 19.53 & 0.76 & 0.0000 & 0.82 & Unknown & \\
\hline 20.65 & 0.86 & 0.0000 & 0.77 & Unknown & \\
\hline 21.10 & 0.75 & 0.0000 & 0.88 & Unknown & \\
\hline 21.22 & 0.60 & 0.0005 & 0.94 & Unknown & \\
\hline 21.32 & 0.40 & 0.0299 & 0.18 & Propofol & Anaesthetic \\
\hline
\end{tabular}

outlet did not correlate significantly and were found in a higher concentration in breath, which might suggest that these VOCs do not originate exclusively from the systemic circulation and are produced locally in the lung.

The concentration of two important VOCs, i.e. acetone and isoprene, that could be informative about the metabolic status of a patient [6] was found to be higher in the outlet gas from the extracorporeal circulation than in the breath of these patients. These two concentrations can differ due to several factors. First, local production in the lung, e.g. by bacteria [17] or lipid peroxidation [18], might lead to a higher exhaled concentration, but this was opposite to what we found. Second, the diffusion capacity may differ selectively between the lung and the extracorporeal circulation for different compounds, which might increase or decrease the breath concentration, but there is no evidence for this for these two compounds. Third, in mechanically ventilated patients there is frequently a profound ventilation/perfusion mismatch in the lung, which might result in a lower exhaled concentration of nonpulmonary produced VOCs due to noncirculated alveoli (e.g. dead space ventilation). The ventilation/perfusion mismatch seems most plausible for acetone and isoprene based on the results presented in this study as VOCs known to originate from blood are found consistently in lower concentrations in breath in this study (table 3 ). This is also in line with previous literature; we were not able to predict changes in glucose concentrations based on exhaled VOC in critically ill mechanically ventilated patients [11]. In a very selected group of critically ill patients the higher amounts of acetone measured in air coming from the external outlet of an extracorporeal life-support membrane could provide possibilities for online monitoring.

Only approximately a third of the VOCs that were found persistently in breath and air from the outlet of the extracorporeal circulation correlated significantly. As discussed earlier, there could be three reasons for this. 1-propanol is one of the VOCs that is found in higher concentration in breath. In general, 1-propanol is considered a contaminant. However, this molecule has also been linked to bacterial metabolism and an 


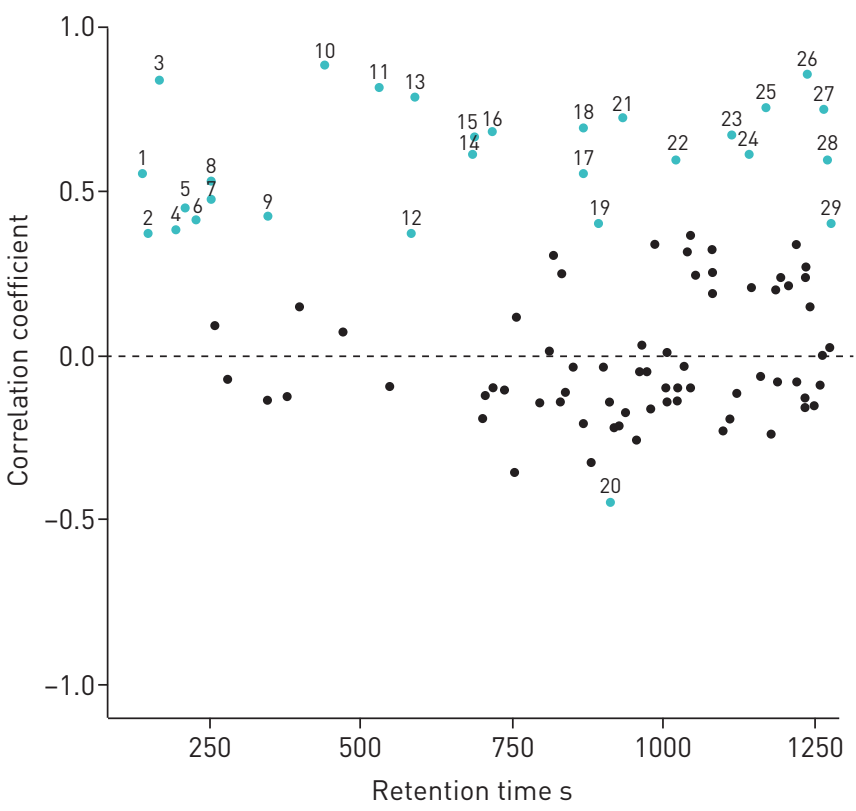

FIGURE 2 Correlation between the concentration of volatile organic compounds (VOCs) in exhaled breath and in air coming from the extracorporeal circulation. The $y$-axis shows the retention time of the VOCs. The $y$-axis shows the correlation coefficient between the concentration of VOCs in breath and in air coming from the extracorporeal circulation. 1: acetone; 2: isoprene; 3: 2-propanol, 1,1,1,3,3,3-hexafluoro-; 4: 1-propanol; 5: pentane, 3-methyl-; 6: pentane, 2,4-dimethyl-; 7: furan, 2-methyl; 8: ethyl acetate; 9: 2,4-hexadiyne; 10: 1-pentene, 2,4,4-trimethyl-; 11: unknown; 12: unknown; 13: unknown; 14: unknown; 15: benzene, chloro-; 16: 3-hexanone, 2-methyl-; 17: 2-propanol, 1,1,1-trichloro-2-methyl-; 18: unknown; 19: pentane, 2,2,3-trimethyl-; 20: unknown; 21: D-limonene; 22: unknown; 23: undecane; 24: unknown; 25: unknown; 26: unknown; 27: unknown; 28: unknown; 29: propofol.

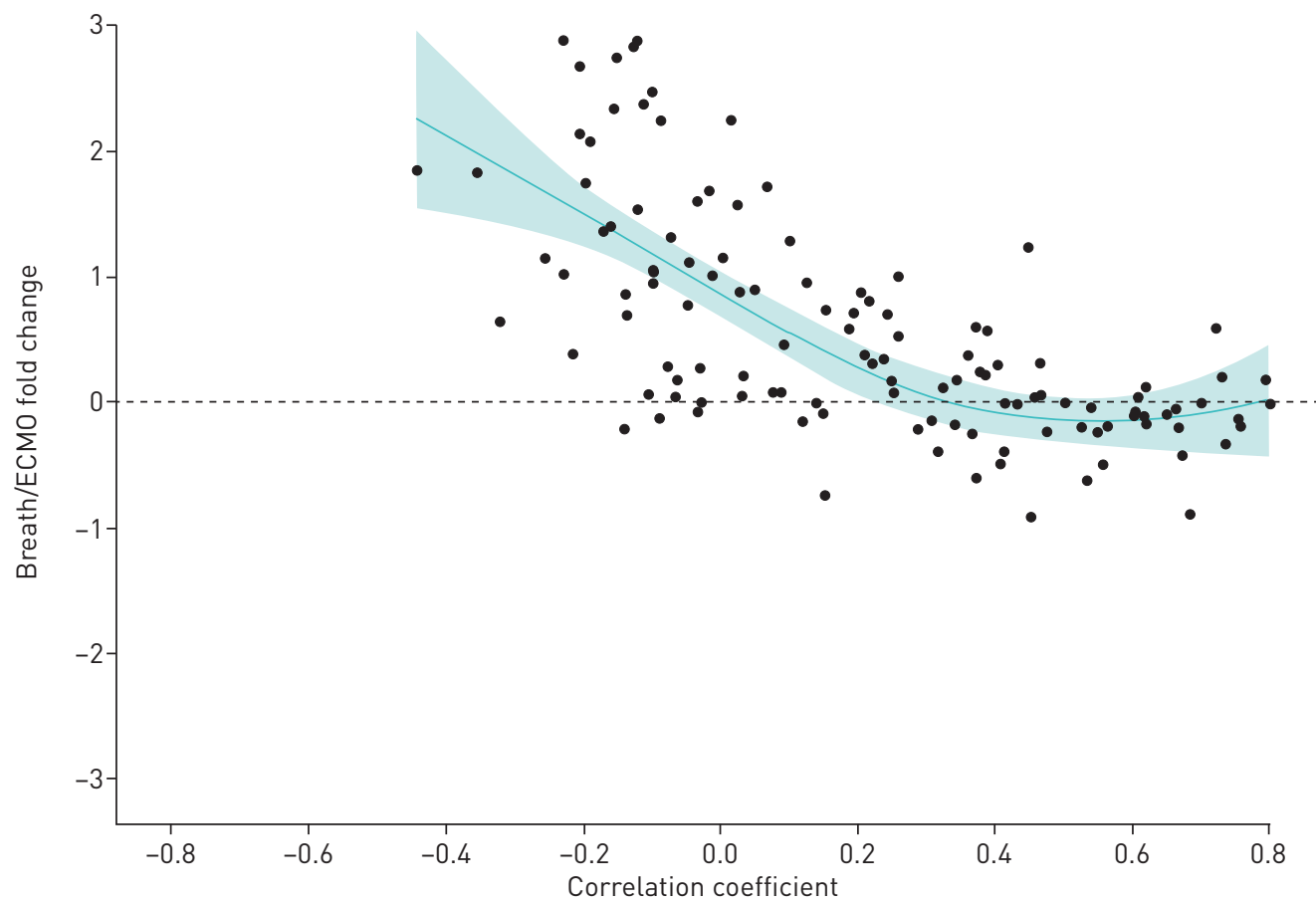

FIGURE 3 Fold change between exhaled breath concentration and extracorporeal air concentration, and the correlation coefficient between the two measurement sites. ECMO: extracorporeal membrane oxygenation; VOC: volatile organic compound. The x-axis shows the correlation coefficient between VOCs in breath and in air coming from the extracorporeal circulation. The $y$-axis shows the fold change in VOC abundance between the two measurement sites. 
inflammatory response in the lung [19]. We speculate that many of the molecules that were not found to correlate are produced locally in the alveoli and airways, and are therefore not detectable in the extracorporeal circulation. This is further supported by the observation that VOCs that did not correlate between the breath and the air from the extracorporeal circulation were more likely to be present in higher concentrations in the breath (figure 3). It should be noted that VOCs from the extracorporeal circulation and from breath can only be compared in a highly selected group of patients and it is unknown how these results translate to other patient groups. However, it seems plausible that for patients with severely damaged lungs, requiring extracorporeal support, the airways and alveoli contribute to a large proportion of the VOCs in the exhaled breath. These results should be confirmed in other populations. We suggest to investigate patients undergoing cardiac surgery as this would allow the comparison in a patient group with relatively healthy lungs. Additionally, further analysis should consider different types of oxygenators and the possibility of using VOCs to detect organ failure other than the lung.

This is the first study to analyse VOCs in the air coming from the external outlet of an extracorporeal life-support membrane using an eNose and GC-MS. The results of this study indicate that this can be done safely, and, based on the molecular identification of the VOCs found, we speculate that there is a potential for monitoring of VOCs that are likely to have a nonpulmonary origin in the extracorporeal circulation. Nonetheless, several weaknesses of the study must be acknowledged. Owing to the pragmatic observational nature of this study, we did not have control over patient selection nor did we distinguish between different membranes used in these patients. In addition, adapters fitted to the external gas outlet of the membranes differed between the different membrane types as manufacturers used their own proprietary designs. Furthermore, we did not tightly control the ventilation parameters and the flow in the extracorporeal circulation, all of which might influence the concentration of the identified VOCs.

\section{Conclusions}

The results from this study support the safety and feasibility of extracorporeal VOC analysis. This study indicates that VOCs of nonpulmonary origin can be measured in exhaled breath and in the extracorporeal circulation. For VOCs that did not correlate between the two measurement sites, the breath concentration was higher, suggesting pulmonary production of these molecules in a highly selected population of critically ill patients requiring extracorporeal support.

Conflict of interest: None declared.

\section{References}

1 Barnett N, Ware LB. Biomarkers in acute lung injury - marking forward progress. Crit Care Clin 2011; 27: 661-683.

2 Boots AW, Bos LD, van der Schee MP, et al. Exhaled molecular fingerprinting in diagnosis and monitoring: validating volatile promises. Trends Mol Med 2015; 21: 633-644.

3 Minh TDC, Oliver SR, Ngo J, et al. Noninvasive measurement of plasma glucose from exhaled breath in healthy and type 1 diabetic subjects. Am J Physiol Endocrinol Metab 2011; 300: E1166-E1175.

4 Lee J, Ngo J, Blake D, et al. Improved predictive models for plasma glucose estimation from multi-linear regression analysis of exhaled volatile organic compounds. J Appl Physiol 2009; 107: 155-160.

5 Boots AW, van Berkel JJ, Dallinga JW. The versatile use of exhaled volatile organic compounds in human health and disease. J Breath Res 2012; 6: 027108.

6 Leopold JH, van Hooijdonk RT, Sterk PJ, et al. Glucose prediction by analysis of exhaled metabolites - a systematic review. BMC Anesthesiol 2014; 14: 46.

7 Bos LDJ, van Walree IC, Kolk AHJ, et al. Alterations in exhaled breath metabolite-mixtures in two rat models of lipopolysaccharide-induced lung injury. J Appl Physiol 2013; 115: 1487-1495.

8 Fens N, de Nijs SB, Peters S, et al. Exhaled air molecular profiling in relation to inflammatory subtype and activity in COPD. Eur Respir J 2011; 38: 1301-1309.

9 Dolch ME, Hornuss C, Klocke C, et al. Volatile organic compound analysis by ion molecule reaction mass spectrometry for Gram-positive bacteria differentiation. Eur J Clin Microbiol Infect Dis 2012; 31: 3007-3013.

10 Kamysek S, Fuchs P, Schwoebel H, et al. Drug detection in breath: effects of pulmonary blood flow and cardiac output on propofol exhalation. Anal Bioanal Chem 2011; 401: 2093-2102.

11 Leopold JH, Bos LDJ, Colombo C, et al. Noninvasive breath monitoring with eNose does not improve glucose diagnostics in critically ill patients in comparison to continuous glucose monitoring in blood. J Breath Res 2017; 11: 026002 .

12 Bos LDJ, Weda H, Wang Y, et al. Exhaled breath metabolomics as a noninvasive diagnostic tool for acute respiratory distress syndrome. Eur Respir J 2014; 44: 188-197.

13 Bos LDJ, Wang Y, Weda $\mathrm{H}$, et al. A simple breath sampling method in intubated and mechanically ventilated critically ill patients. Respir Physiol Neurobiol 2013; 191C: 67-74.

14 Peters AL, Gerritsen MG, Brinkman P, et al. Volatile organic compounds in exhaled breath are independent of systemic inflammatory syndrome caused by intravenous lipopolysaccharide infusion in humans: results from an experiment in healthy volunteers. J Breath Res 2017; 11: 026003.

15 Leopold JH, Abu-Hanna A, Colombo C, et al. Factors influencing continuous breath signal in intubated and mechanically-ventilated intensive care unit patients measured by an electronic nose. Sensors 2016; 16: 1337. 
16 R Core Team. R: A Language and Environment for Statistical Computing. Vienna, R Foundation for Statistical Computing, 2014

17 Bos LDJ, Sterk PJ, Schultz MJ. Volatile metabolites of pathogens: a systematic review. PLoS Pathog 2013; 9 e1003311.

18 Kneepkens CMF, Lepage G, Roy CC. The potential of the hydrocarbon breath test as a measure of lipid peroxidation. Free Radical Biol Med 1994; 17: 127-160.

19 van Oort PMP, de Bruin S, Weda $\mathrm{H}$, et al. Exhaled breath metabolomics for the diagnosis of pneumonia in intubated and mechanically-ventilated intensive care unit (ICU)-patients. Int J Mol Sci 2017; 18: 449. 